\title{
EVALUATING THE BENEFITS OF ELECTRONIC COMMERCE IN SMALL AND MEDIUM ENTERPRISES
}

\author{
Peter Marshall and Judy McKay \\ Mt Eliza Business School \\ Melbourne \\ pmarshal@mteliza.com.au \\ Monash University \\ Melboume \\ judy.mckay@sims.monash.edu.au
}

\begin{abstract}
This paper outlines and analyses the behaviours of small and medium enterprises with respect to the evaluation of electronic commerce investments, and the subsequent realisation of the anticipated benefits from those investments. The responses of executives who participated in the study suggested that on-going involvement in electronic commerce did not come cheaply. Nonetheless, our study suggests that there were generally ad hoc approaches to evaluation of the proposed electronic commerce investments, almost non-existent post-implementation reviews, few measures of success, and generally speaking, there was little evidence of there being proactive management of the realisation of benefits of those investments. Perhaps not surprisingly, the group interviewed seemed somewhat disappointed with the outcomes of their electronic commerce initiatives. The implications of these findings are discussed, particularly for countries where small and medium enterprises contribute a large proportion of total economic activity, and where thus it is vital for small and medium enterprises to successfully engage in electronic commerce if the country is to derive the benefits of the new economy.
\end{abstract}

Keywords: electronic commerce, IT evaluation, benefits management, small and medium enterprises

\section{INTRODUCTION}

It appears that somewhat of a dichotomy exists in many contemporary organisations with respect to the question of investment in information and particularly in information technology (IT). On the one hand, discussion of the new information-based economy and the promise of the new e-business domain lead inevitably to enormous faith being placed in IT, or perhaps more accurately, on the critical, appropriate utilisation of IT to deliver business benefits. Such faith is illustrated by quotes such as:

"Across all industries, information and the technology that delivers it have become critical, strategic assets for business firms and their managers" (Laudon and Laudon 2000).

But such enthusiasm is tempered by another view or concern that IT is not delivering on its promises, that it is "oversold and under delivered" (Earl 1994), and that demonstrating the business value of IT investment is difficult in many instances. This concern that managers do not perceive that they are deriving value for money when it comes to IT investments is troubling when information and IT are often presented as the very backbone of the new economy. Such cynicism is reflected in quotes such as:

"There are many different ways to ruin a company. Speculation is the fastest, IT is the most reliable" (Kempis et al. 1999).

Why do we experience such conflicting attitudes? Why is there so often a gap between aspirations with respect to IT, and the reality of IT implementations in many organisations? More importantly, can a sensible way forward be found, such that managers can develop greater confidence in their IT investment decisions?

This paper presents and discusses the results of a survey on the practices of small and medium enterprises (SMEs) with respect to the evaluation of their electronic commerce (EC) investments (both pre-investment and post-implementation) and their behaviours in terms of managing the realisation of the anticipated benefits of those EC investments. The study aimed to find out whether, and how, managers in SMEs evaluated proposals for investment in EC technologies, and whether they have mechanisms in place to ensure the realisation of business benefits to the organisation once that investment has been made. Our aim was to better understand whether these managers felt they were deriving "value for money" with respect to their EC initiatives, and to better understand whether (and how) expected benefits from EC investments are realised in practice.

For the purpose of this study, the focus was on EC investments, and thus a distinction was drawn between EC and IS/IT investments. Some would argue that this distinction is false, that it is unfruitful to attempt to separate out interorganisational and intraorganisational business processes and activities, and more specifically the IS/IT investments which support and facilitate such business transactions, interactions and decision making (Zwass 2001). While we concede that such a distinction is not always nor necessarily clear cut, and that indeed, over time, it may fade altogether, previous research has lead us to the view that firstly, owner-managers of SMEs are quite conceptually clear on those IS/IT investments which have been initiated essentially through the advent of the Internet (see Marshall et al. 2000, Valli and Marshall 2001, for example), and those which are being made to 
support more traditional business activity. Secondly, experience has suggested that the Internet has directly motivated IS/IT expenditure in SMEs, in some cases in organisations where comparatively little IS/IT expenditure had ever taken place before: it was on this type of investment that we wished to focus. Thus, the former we call "EC investments" for the purpose of this research, essentially "front office" investments which enable an Internet presence, are required to sustain that presence, and which were essentially driven by the rise of the Internet.

The authors subscribe to the view that benefits do not automatically accrue to an organisation from investment in technology. Rather, the view held is that technology investment should be guided by clear business objectives indicating the need for IS/IT for their achievement. Furthermore, not only should IT requirements be based on business imperatives, but they should also be subjected to a rigorous, strategy-driven process of on-going, multifaceted evaluations linked to proactive benefits realisation, which acknowledge and imply the need to be linked to organisational change management. Thus, an IS/IT strategy process links IS/IT investments to business strategy and then these proposed investments are subjected to a process of evaluation, benefits management and change management. In this way, through appropriate IS/IT investment and sound governance of those investments will business benefits accrue to the organisation (McKay and Marshall 2001). Thus, pre-investment, benefits identified as stemming from an EC investment must be regarded as potential benefits only (that they are expected to accrue to the organisation), but subsequent events and managerial actions will impact on whether or not they are actually realised. Arguably, appropriate evaluation practices and proactive management of the realisation of benefits will help translate potential benefits into benefits derived for the organisation (Ward et al. 1996) (see Figure 1).

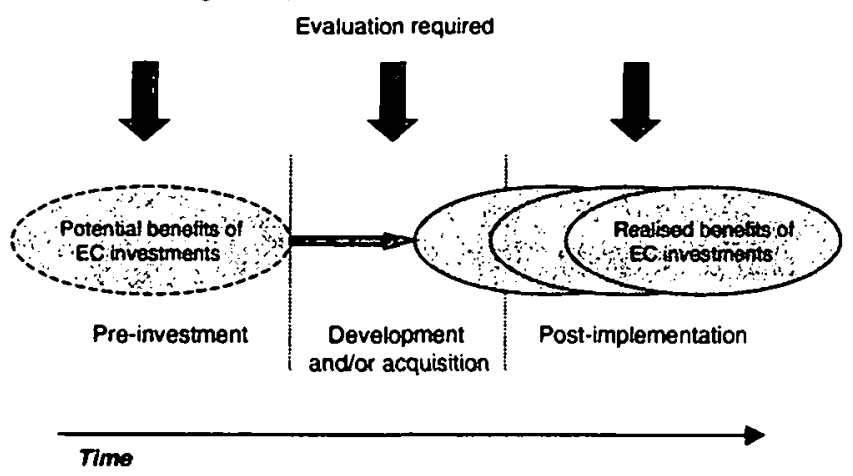

Figure 1: Need for Evaluation and Active Realisation of Benefits from EC Investments

\section{BACKGROUND}

There can be little doubt that EC has had, and will continue to have, a significant impact on the commercial, social and economic fabric of society. The past decade has seen exponential growth rates in most metrics of EC (US Department of Commerce 1999; Andersen Consulting 1998, DOCITA 2000a), and generally speaking, most forecasts predict that this growth will continue, if not increase, over the next few years (DOCITA 2000b, Emst \& Young 2000a). This rise in the importance of the Internet both as a source of information exchange and commerce leads us inexorably closer to a truly global community, and hence notions such as globalisation and a global economy increasingly manifest themselves in actual commercial and information exchanges.

For small and medium enterprises (SMEs), the Internet has much to offer as a business vehicle as it can serve as a relatively efficient and effective channel for information provision and exchange, advertising, marketing, completing transactions, and in some cases facilitating or directly supporting the distribution of goods and services to global trading partners and customers (Czerniawska \& Potter, 1998, Emst \& Young, 2000b, OECD 1998). However, concerns are being voiced in many quarters about the relatively slow uptake of electronic commerce by SMEs (Small Business Index 1999). It appears that SMEs are yet to be convinced of the merits or potential of EC, nor do they have appreciation of the value of global communication and information infrastructures (Behendorf et al 1996). Some pundits argue that SMEs do not always seem to appreciate that ignoring EC (because the current level of transactions is relatively low) puts them at risk of becoming uncompetitive in the medium and long-term, and hence of failing in the future (Crawford 1998), perhaps succumbing to more aware and aggressive international operators. This is of particular concern in counties and regions where a substantial proportion of business (and hence economic) activity can be attributed to the enterprise of SMEs. In such countries and regions, then, it could be argued that becoming a vibrant player in this new information economy, will rely on SMEs becoming a part of that growth and development. If the currently perceived barriers to involvement in EC are to be overcome, then it would seem that well integrated and embracing strategies that take cognisance of a range of interacting challenges and issues are vital. In addition, being persuaded of the merits of EC and feeling empowered to manage their EC investments such that benefits 
for the business are realised may be vital steps in encouraging appropriate levels of participation in EC amongst SMEs.

\section{RESEARCH APPROACH}

The research reported in this paper is the first stage of a planned programme of research into the management and realisation of benefits from electronic commerce (EC) investments. This was a partly exploratory, partly descriptive study, aimed at finding out about current practices amongst SMEs with respect to the evaluation and realisation of benefits from EC investments. The research was deemed to be mainly exploratory for a number of reasons. There was little published literature to provide insights into this area, a point previously noted in the background to this paper. As researchers, we were aiming to become more familiar with the practices in organisations, and wanted to become more confident in our knowledge of "what was actually going on". It was believed that through establishing a broad "picture" of current practices, the beliefs of the researchers would be confirmed or disconfirmed, questions and issues would emerge for a subsequent, more systematic enquiry, as would appropriate directions for future research (Neuman 1997). However, the study could also be claimed to be descriptive, in the sense that it aimed to describe practices, provide a "picture", and document information about an issue. Given these factors, an exploratory/descriptive study using survey interview method gathering both qualitative and quantitative data seemed an appropriate way to proceed (Neuman 1997). While some writers express concerns about the suitability of survey interview method for exploratory research (Fowler and Mangione 1990), there is generally more support for its usefulness in capturing pictures of practices or descriptions of real-world situations (Galliers 1991, Bryman 1989, Leedy 1993).

Thus, the major purpose of the research can be stated as follows:

- to identify current practices amongst SMEs with respect to the evaluation and realisation of benefits from EC investments;

- to investigate whether SMEs attempt to, and are able to accurately assess the impacts of their EC investments; and

- to see whether SMEs have a methodical approach to benefits management.

The survey was developed from an instrument previously used by Ward et al. (1996), but was modified somewhat to make it more suitable for the context of this particular study. This survey was limited to EC investments (as previously defined), and not to IS/IT investments in general as the original one was. Secondly, the focus was on SMEs, not large organisations, and some changes were required to reflect this. Thirdly, as the original survey was intended for IT Directors or Chief Information Officers, some modifications were required for our intended target of general senior managers. The fourth point to note is that the survey in this research was conducted by phone, not by mail, as in the original research.

The nonprobability sampling technique used in this research was convenience sampling (Leedy 1993). Nonprobability sampling means that there can be no guarantees that participants in the study are representative of the population at large, and a convenience sample is selected on the basis of availability to the researcher or happenstance (Neuman 1996, Bryman 1989). Clearly in studies requiring statistical analyses, this approach would be inadequate, but given the exploratory nature of the research and the interest of the researchers in getting a "feel" for industry practices with respect to benefits management, it seemed adequate for our purposes, especially given some of the defining criteria imposed on participants (and discussed in the next paragraph). Furthermore, as no attempt was planned to make statistically-based deductions from the data collected, and as any quantitative results are expressed only as proportions or frequencies, a convenience sample seemed adequate for the purposes of this study.

The participants were all enrolled in the MBA programme at the researchers' university and to be included in the study had to meet all of the following criteria:

- they had to work in, or direct, or own a non-government SME;

- they had to demonstrate that they were at least in senior middle management ranks or above;

- they had to be in non-IS/IT management (i.e. senior line managers or in a senior staff function other than IS/IT);

- their organisation had to have implemented at least a rudimentary EC system (a "publish" web site as a minimum);

- they had to have had direct involvement in the evaluation and implementation of the EC investment, and with its subsequent management;

- they had to be willing to participate in a phone interview.

Out of the total cohort of $43 \mathrm{MBA}$ students potentially available to the researchers, 18 met all the criteria and were selected for inclusion in this study. Clearly there is no way of knowing whether this group is representative of the wider population, and indeed, the decision to study an MBA may indicate an atypical SME manager. 
However their involvement in EC investment decisions may suggest their responses are knowledgeable of evaluation practices with respect to EC investments. Participants were telephoned at a prearranged time and location, and were interviewed by the researchers guided by the survey questionnaire. While there were occasions when the interview became more expansive, by and large, the interviews were quite structured, and were limited in the elaborations sought. The interviews were conducted during April and May 2000. While the researchers did clarify the meaning of "EC investment" for the participants, no attempt was made to define "benefits management" or "benefits realisation", thus enabling participants to apply their organisational understanding of benefits in their responses. At the time of the interviews, the participants had not studied either IT Evaluation or Benefits Management in their MBA coursework.

The survey contained a total of 57 questions, a mix of closed questions (yes/no), scale items (multiple choice, ranking, etc.) and with some open-ended items providing opportunities for descriptions, explanations, justifications and so on. There were four broad sections in the survey. The first aimed to elicit background information on the participants and their organisations. The second section contained general questions about the nature of their involvement with EC, their expenditure on EC, and their perceptions about the benefits of EC. The third section went into more details regarding the planning that was done prior to making the EC investment decision, while the fourth section concentrated on the realisation and management of benefits from the EC investment.

\section{RESEARCH FINDINGS}

\section{Background}

Of the 18 participants, 12 regarded themselves as non-IS/IT managers, with job titles such as CEO, Business Manager, and Financial Manager, for example. The remaining 6 preferred to describe themselves as hybrid managers, with an excellent knowledge of IS/IT although officially now employed in a senior, non-IS/IT staff management position. More than half the participants (12) worked in medium-sized enterprises, with the remainder divided evenly between small and micro enterprises. They were drawn within a variety of industry sectors including such diverse fields as tourism, recreation and hospitality, business consultancy and training, environmental services, marine services, engineering, logistics, import/export businesses, and medical and welfare services.

\section{Involvement in Electronic Commerce}

The executives were asked to identify their organisation's level of involvement with EC. The levels described for them were based on those of O'Connor and Galvin (1998) who defined four levels as publish (essentially a web site enabling one-way communication only), interact ( a web site enabling two-way flows of information), transact (a web site supporting the completion of full business transactions including payment), and integrate (a web-enabled network of trading partners integrated with internal business processes and systems). The majority of these organisations are still at relatively immature levels of electronic commerce currently, but it is interesting to note that 3 of the larger businesses were already engaged in full-scale B2B and B2C electronic commerce through their involvement at an Integrate level (see Figure 2 below). Not surprisingly therefore, IT was seen in a support or key operational role in their organisation by most participants, although 5 suggested that IT was being deployed strategically by their organisations, and 4 claimed it was being used in a developmental capacity.

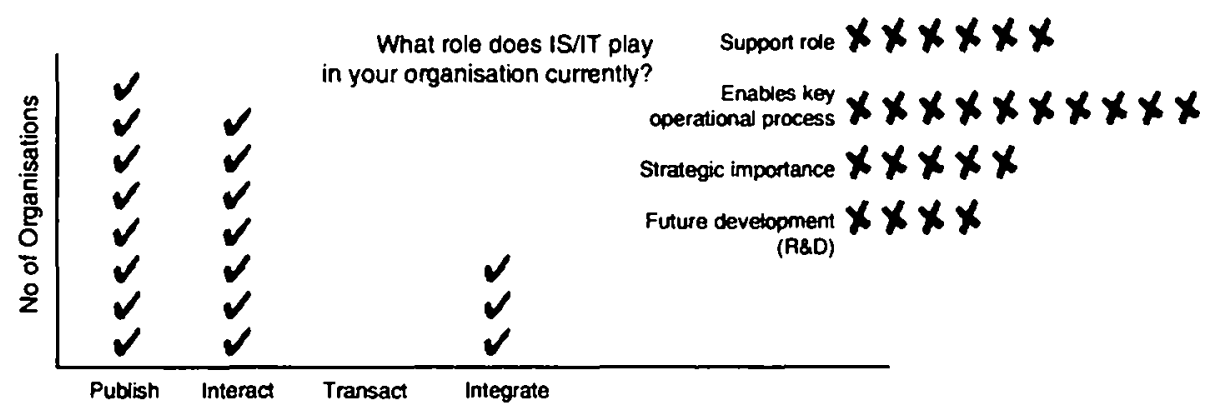

Figure 2: Level of Involvement with EC

Start up costs for EC were defined for the participants as including the costs associated with hardware purchases and/or upgrades, software purchases (including development and/or tailoring costs if appropriate), and consultancy fees. The estimates of these costs are detailed (in Australian \$) in Figure 3 below. While estimates of start-up costs ranged from $\$ 2500$ to more than $\$ 100,000$, it is interesting to note that while only 3 
organisations were involved in more sophisticated activity than interacting with customers on the web, 6 organisations had reportedly spent more than $\$ 100,000$ in establishing electronic commerce in their organisations. Our study would suggest that while some organisations are able to engage in EC with relatively little expenditure, for others, quite extensive costs are involved.

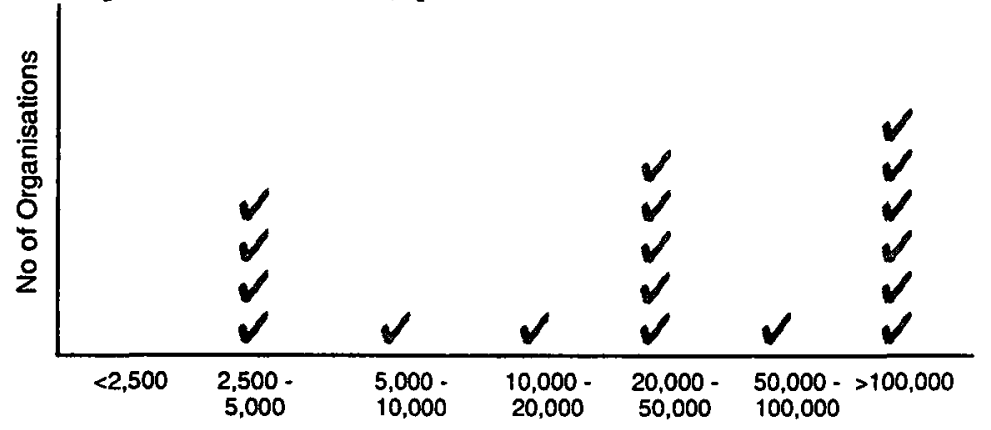

Figure 3: Estimated Start-up Costs for EC

For some organisations there are also expectations of considerable on-going costs for operations and maintenance of the EC activity. On-going operations and maintenance were defined to include ISP and ASP costs, web site maintenance costs, order fulfillment costs and so on. Figure 4 below details the executives' estimates of their organisation's annual expenditure.

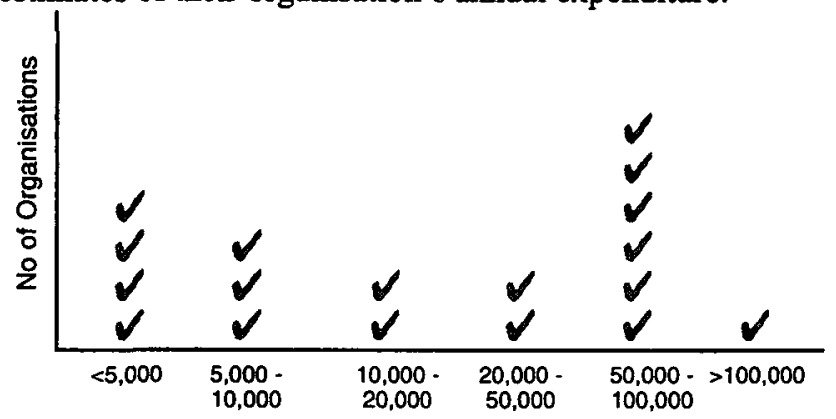

Figure 4: Estimated Annual Expenditure on Operations \& Maintenance for EC

In contrast to the costs of being involved in electronic commerce, participants were asked to estimate the proportion of weekly revenues generated through their electronic commerce involvement. Revenues generated was defined to include direct web sales as well as orders/sales motivated by the web site. Details are contained in Figure 5 below. Of interest is the high proportion who claim not to be generating any revenues, although this may be a function of the fact that a large proportion $(>40 \%)$ of organisations in this study at this stage, had established a publish-only web site. Of concern too with these estimates of revenues is how accurately webmotivated transactions are able to be identified amidst all other business activity ${ }^{8}$.

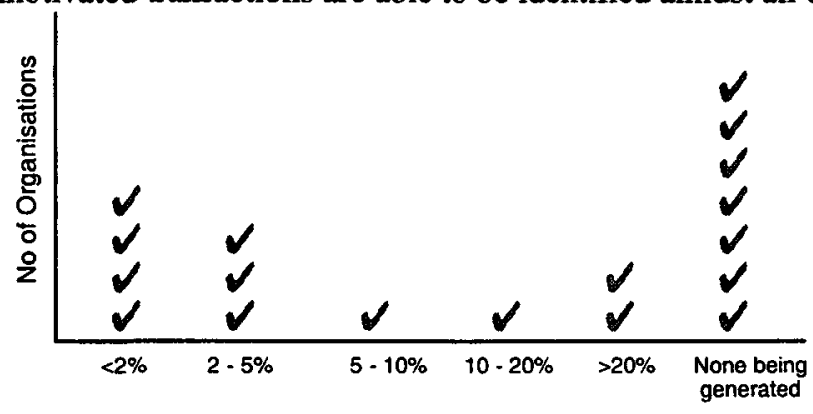

Figure 5: Proportions of Weekly revenues generated from EC

In terms of cost savings, a scattered picture emerged of savings in telephone and fax costs, post, printing and paper, and reduced costs of advertising over the Internet. Other reported savings were from time saved, lower transaction costs, and lower service delivery costs. Once again, however, by far the most common response was that no cost savings had been achieved (and 1 respondent was uncertain as to whether costs savings had been achieved), and one executive wryly added that "The cost of web site maintenance more than overrides any cost savings achieved". Figure 6 below contains the details of participants' perceptions of cost savings.

\footnotetext{
${ }^{8}$ A previous study of car dealers found that no mechanisms existed to reveal web-motivated "walk-in" customers and subsequent sales (see Marshall et al. 2000).
} 


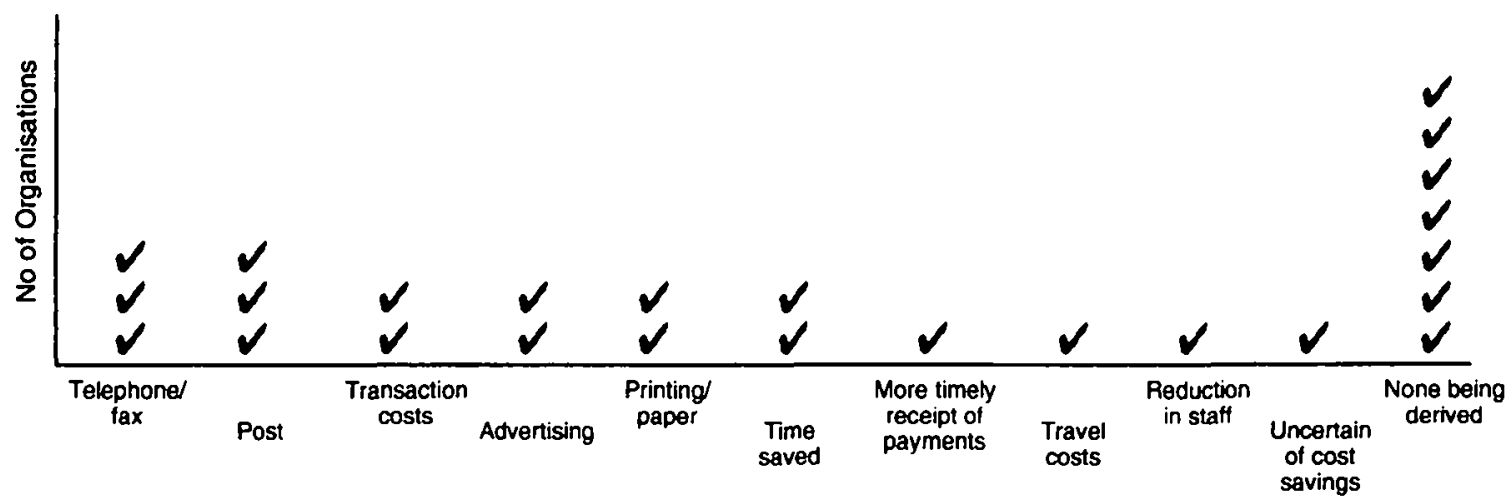

Figure 6: Cost Savings Derived through EC

Although the participants did not paint an overly optimistic view of their experiences to date in terms of increasing revenues and reducing costs, they nonetheless perceived electronic commerce to offer a number of potential benefits (both tangible and intangible) for their organisations. Further details of the participants' responses are provided below in Figure 7. Access to, and provision of timely, relevant information was the most widely recognised benefit of electronic commerce, and interestingly, this may not contribute directly to increasing revenues or reducing costs. However, many of the remaining perceived benefits (reduced cycle time, improved efficiencies, etc.) would be expected to translate directly into improved organisational performance. Given the contrast then, between their perceptions of benefits and their relative lack of deriving costs savings or increased revenues, it begs the question of how confident the participants were that they were actually successfully realising these perceived benefits. There was an even range of responses to this from "not at all confident" to "very confident".

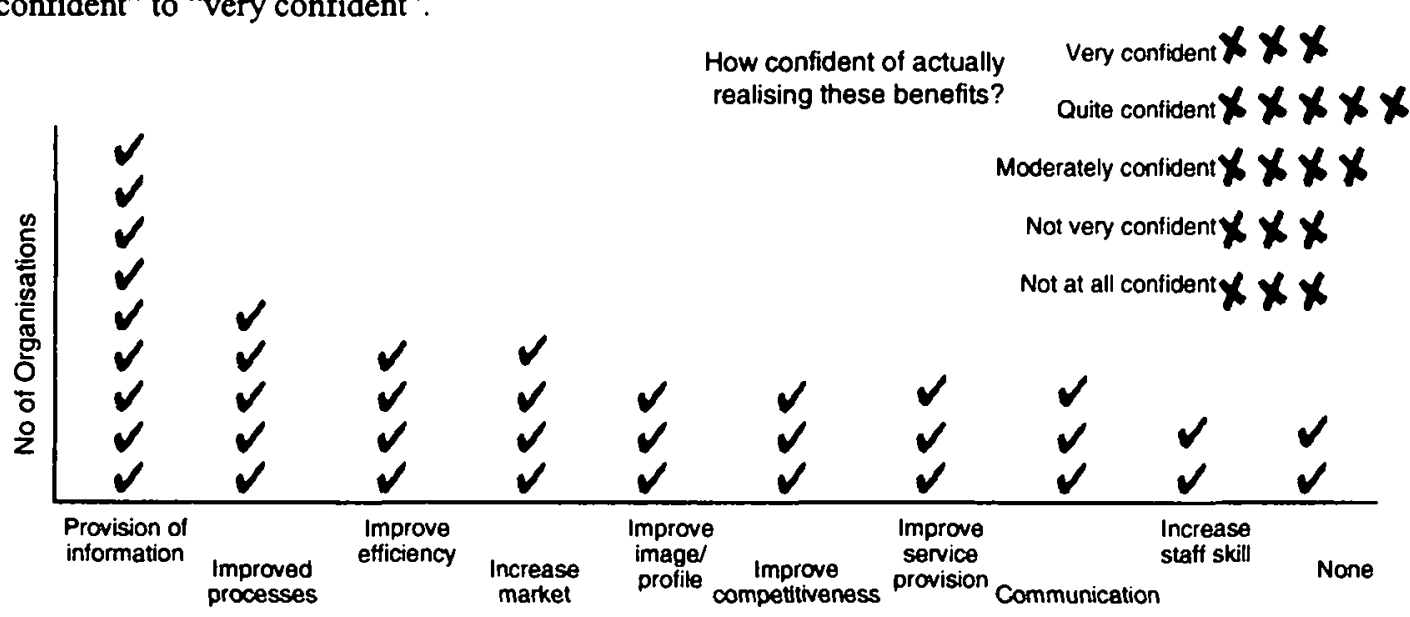

Figure 7: Major Perceived benefits of EC

The expressed reasons for their confidence that benefits were being achieved were mixed. Those who were not very confident commented that they had not had nearly the response they expected following their EC investment (for example, they were not getting as many "hits" or customers as forecast), or admitted that they had not assessed whether benefits were being derived. Many commented in their replies that they were finding it difficult to measure where and what benefits were being achieved. By contrast, those expressing great confidence were usually able to cite some metric having been applied, such as improved customer satisfaction surveys following the EC initiative (and arguably directly attributable to that investment). It must be noted however, that some participants expressing confidence could not actually substantiate their feelings with any tangible evidence, and seemed to be relying on "gut feel".

When questioned about their main concerns with respect to their EC initiatives, their responses seemed to reflect a relatively high awareness of some current concerns surrounding EC. For example, the single most mentioned issue was "Is electronic commerce worthwhile? Will electronic commerce contribute benefits to my business (either reducing costs or increasing profitability)?". Security concerns, including the need to maintain confidentiality of important corporate and customer data, and technical issues were also reported to be of concern to a number of respondents, particularly those in micro and small enterprises and those in not-for-profit organisations. Figure 8 below details the concerns expressed. 


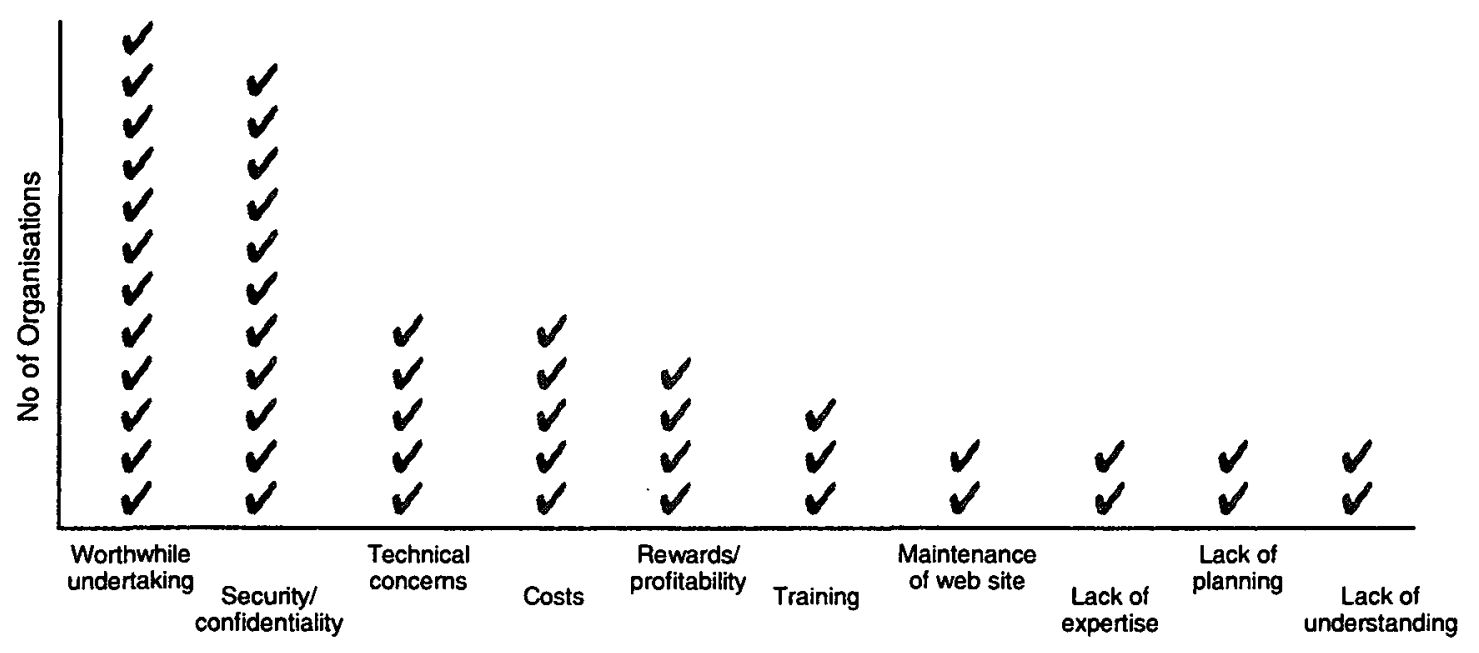

Figure 8: Major Concerns with respect to EC

\section{Planning Considerations for EC}

The SMEs represented in this study were in large agreement over the main drivers of their involvement in EC (see Figure 9 below). Issues to do with competitiveness (EC was seen as essential to match or better their competitors) and market forces were by far the most frequently cited reasons for engaging in EC. Participants reported increasing awareness of and interest in the Internet amongst both their customers and trading partners and a number reported that they viewed EC simply as an extension of their business (it was a part of being in business). In contrast to previous studies (Marshall et al 2000), comparatively few (3) said there were involved in EC because "everyone else is doing it". Greater business maturity seem to underlie their decision-making about making investments in EC than was revealed in previous case studies (Marshall et al. 2000).

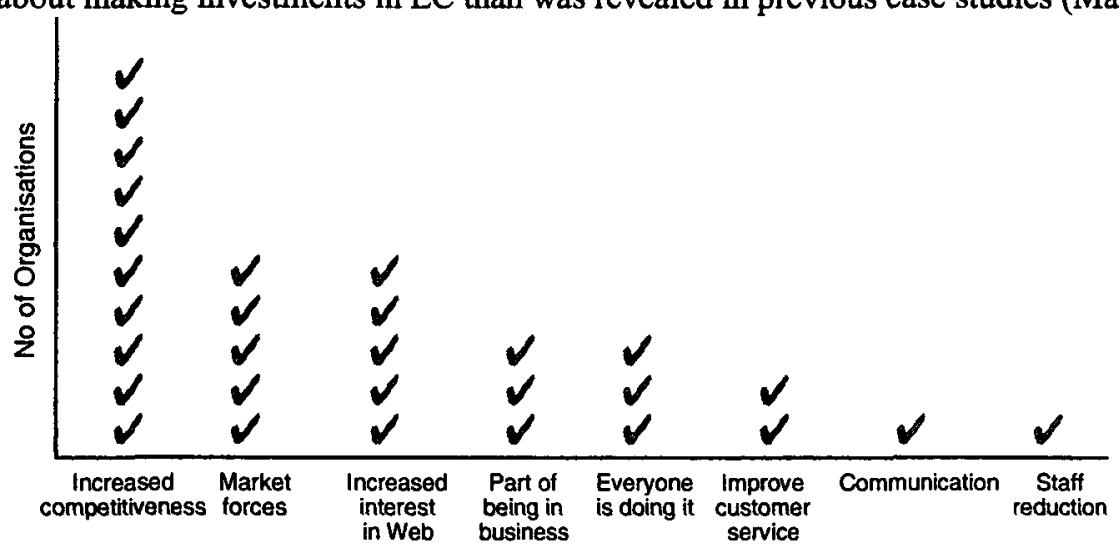

Figure 9: Drivers of EC Investments

Despite the seeming business imperatives driving the EC activity of these SMEs, a significant proportion of respondents $(>50 \%)$ did not include EC considerations in their business plans, nor did they have any apparent mechanism for linking their EC investments with their business objectives. Only 4 participants (22\%) said that planning EC initiatives was an integrated part of their business planning activity.

Planning was conducted for individual EC projects. Economic and financial benefits figure highly in their planning activity, as do benefits that would accrue from better management of their customers. Other motivators seem to be associated with competitiveness and the promotion of brand and/or corporate image through EC initiatives. Indeed improving their image or profile and signalling to competitors were important intangible benefits that were considered. Figure 10 below details to planning of benefits in these EC ventures. 


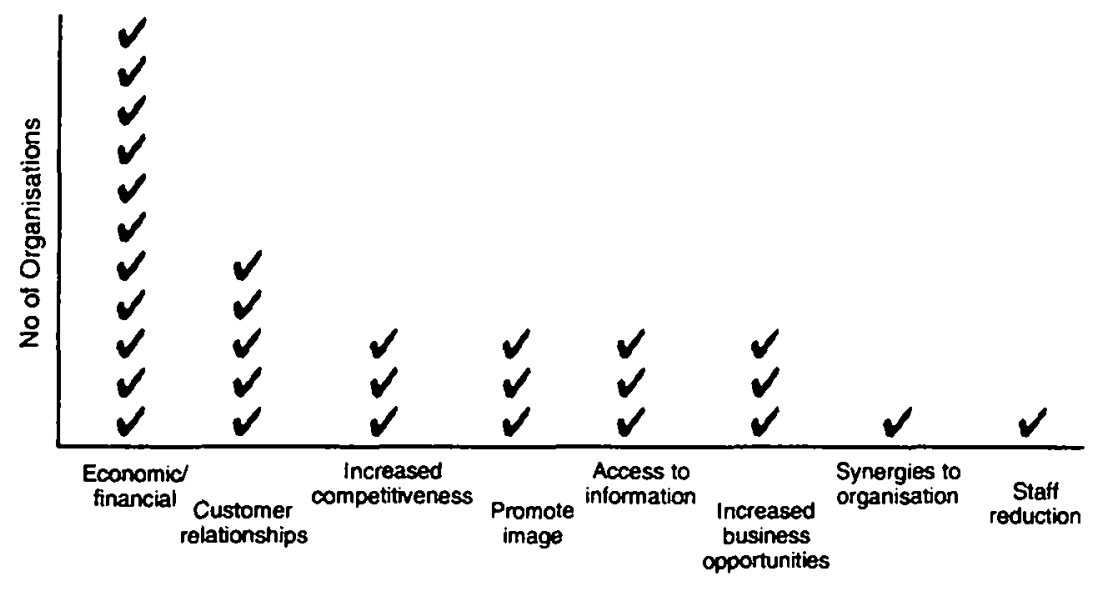

Figure 10: Benefits Considered in Planning EC

Participants were asked a number of questions about their up-front evaluation practices, and a somewhat mixed response emerged. Five participants said their organisations used a fairly traditional ROI and cost/benefit approach to their evaluations. Two participants said evaluation was part of building a business case for EC prior to investment, and one respondent had sought professional advice prior to making the investment. For the remaining organisations, a much more haphazard approach seems to a been adopted. Five said they had relied on "gut feel", essentially the beliefs of their management team or the project champion, and thus no formal evaluation had been employed. Two had sought advice from other similar organisations, two had sought advice from their customers, and two had not done any evaluation at all. One respondent said the only criterion had been the time to implement (they wanted the web site quickly) while one other participant said that evaluation had been based solely on perceptions of the ease of maintenance of the proposed EC project.

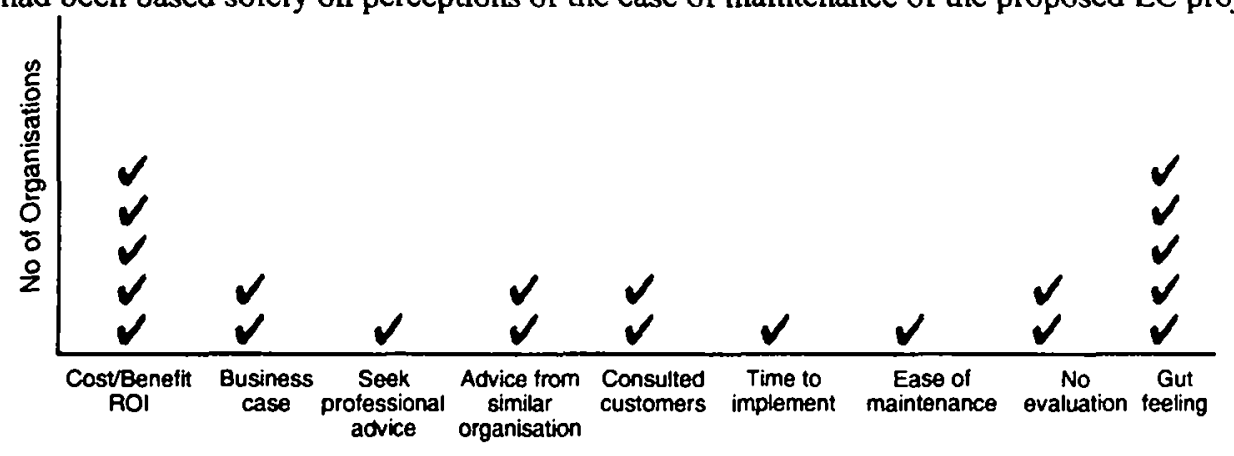

Figure 11: Approaches to Up-front Evaluation of Proposed EC Investments

Generally speaking, however, only 3 participants (17\%) expressed satisfaction with their approach to evaluation. With all the wisdom of hindsight, many now recognised some shortcomings in the approach they had adopted. There were concerns expressed that they felt they needed to do much more research up-front (2), they had grossly overestimated the benefits that would accrue (4), they had overstated expected hits on the web site (and hence their ability to raise revenues from advertising) (3), they realised they had to spend much more in marketing their web sites and hence costs had blown out, to the point where one respondent commented that "More than six months after implementation, we have lost control of the costs". One executives also acknowledged that there had been no sense in which pre-investment evaluation had been linked to their postinvestment desired outcomes. Figure 12 below summarises some of these concerns. 


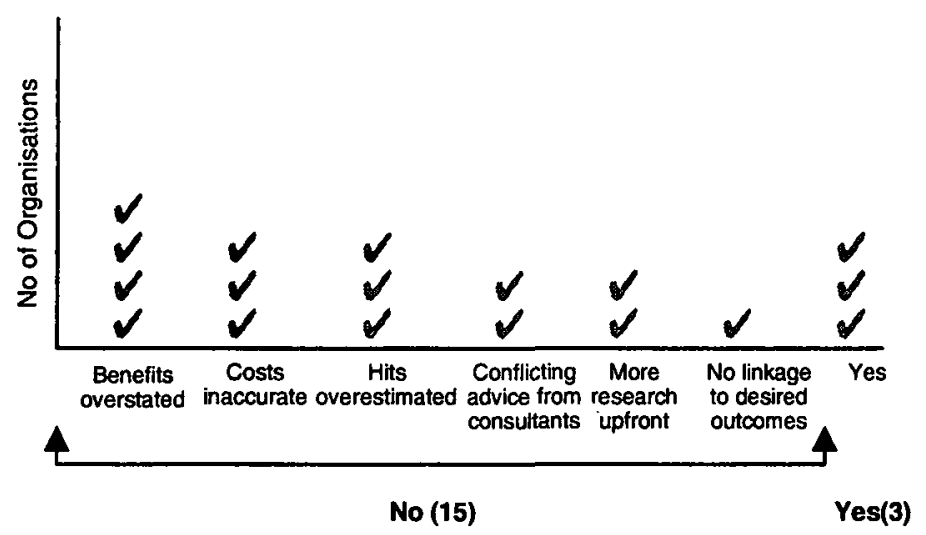

Figure 12: Perceived Helpfulness of Approach to EC Evaluation Employed

Not only was there some concern amongst executives about their evaluation practices, but there were additional concerns about the efficacy of the approach used. So, for example, 13 respondents (72\%) felt that their evaluation process had failed to identify all possible or potential benefits from their EC investments, and perhaps more importantly, felt that they had been unable to satisfactorily quantify the benefits identified. 11 of the respondents $(61 \%)$ conceded that maybe benefits had been overstated in order to ensure approval was given for the project.

Planning for the realisation of identified benefits also proved to be of some concern. In 12 of the organisations $(67 \%)$, no one was assigned responsibility for realising the business benefits claimed in the justification. In those cases where someone was allocated that responsibility, the types of expectations held of that person were a post-completion audit (1), training (2), processing orders on a daily basis (1), controlling costs (1), and "keeping watch on the web site" (1). When asked how they would ensure that the EC initiative would deliver benefits to all relevant stakeholders, a variety of responses were received (see Figure 13). It is interesting to note that 7 organisations (39\%) were just assuming benefits would be delivered, thought that a nice web site was all that was required, or were willing to leave it to chance.

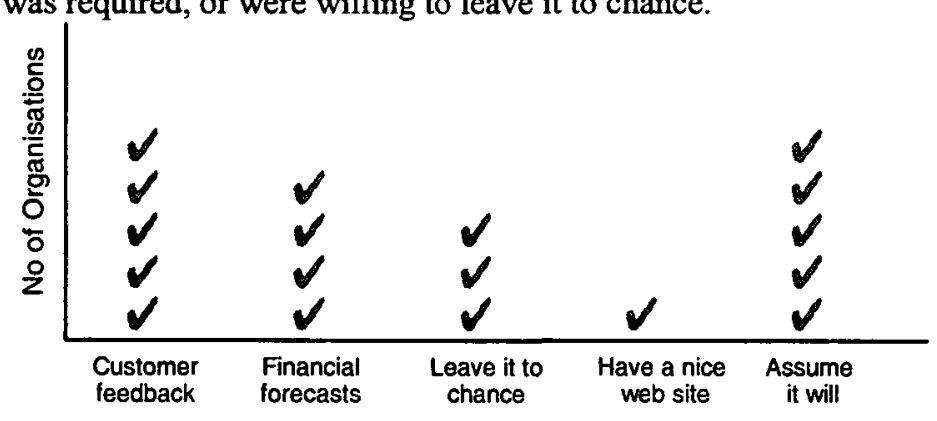

Figure 13: How do you ensure EC initiatives deliver benefits?

Participants were also questioned about whether organisational changes (such as changes to structure or creation of a new department, etc.) or process changes were planned to accommodate the EC initiatives. Varied responses were received indicating that planning of such changes sometimes took place before approval of the investment was given, but there was a clear indication that planning change also went on during the design and implementation stages. Of interest to note was the fact that 8 respondents (44\%) still claimed that changes were still being planned after the web sites and associated systems were operational, perhaps indicating that a reactive approach to change was being adopted in a substantial proportion of the cases.

\section{Realisation and Management of Benefits from EC}

15 of the respondents ( $83 \%$ ) agreed that they had no formal plan to ensure the realisation of benefits from the EC project. (A limitation of the research was perhaps our failure to find out what form the plan took in those three organisations who suggested that a delivery plan did exist). The executives interviewed overwhelmingly felt that responsibility for delivering benefits lay with senior management and to some extent with line/departmental managers, but were generally less clear as to precise procedures in place to ensure the benefits identified preinvestment were actually delivered post-implementation. 6 of the executives (33\%) admitted that in reality, no steps were taken to ensure the realisation of benefits. Other respondents claimed that web site statistics were analysed in some way, but only one respondent then added that this analysis was then considered against objectives in the organisation's strategic plan. The others conceded that such analysis still may not ensure that 
all stated anticipated benefits were actually realised. Two of the executives reported six monthly postimplementation analyses of performance, which they argued identified where benefits were occurring and which benefits were not being realised. A third organisation claimed to have rigorous, systematic post-implementation measures in place which gave it confidence in claiming that many of the anticipated benefits were being delivered.

Participants in the study were asked questions about what constituted "success" with an EC project (see Figure 14). 3 respondents (17\%) considered the impact of the EC initiative on sales, with 2 defining success as increased sales and/or revenues generated on-line, with the third, comparing total sales performance (on-line and traditional channels) post-implementation against historical data. This organisation was willing to attribute an upward trend to the EC project, although the executive did concede that the success may actually have been achieved in the traditional sales channels. 3 organisations defined the EC initiative as successful if project objectives were met, 2 others (22\%) relied on market feedback, while 2 others looked to (upward) changes to service levels as indicative of success. Of concern, however were the 8 organisations $(44 \%)$, who simply had not defined success, who did not make any measurements, and who sometimes complained that it was very hard to measure success.

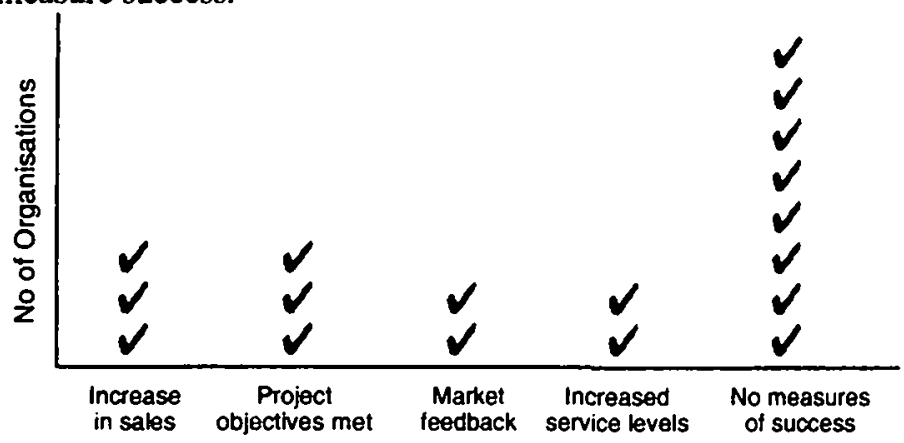

Figure 14: How do you measure success with EC investments?

The executives were also questioned about intangible benefits, specifically how they knew they were achieving intangible benefits, and whether they attempted to quantify intangibles. $12(70 \%)$ agreed that intangibles should be included in considerations of benefits derived and the success criteria for EC, but only 11 claimed they had tried to quantify such benefits. When asked how they did this, the general answer (10 out of 11 ) was that they were still attempting to work out appropriate ways of quantifying intangible benefits! 7 organisations (39\%) relied on informal feedback or anecdotal evidence as indicative that intangible benefits were being achieved, 3 looked to changes to business performance, but again, the larger group (44\%) admitted they had no idea as to whether they had achieved or were achieving any intangible benefit from their EC investment.

Only 7 organisations conducted (or were in the process of developing) formal post-implementation reviews. These were typically in the form of committee assessments, 3-6 months after the implementation of the web site and associated systems. The stated objectives of these reviews were most often project management effectiveness (7), and technical conformance (6), with only 4 organisations seeking to confirm the delivery of benefits to the organisation, and 2 stating that they were just trying to check that the web site was doing the job required of it. What needs to be remembered at this juncture are the 11 organisations $(61 \%)$ who do not conduct any formal post-implementation reviews whatsoever (see Figure 15). 


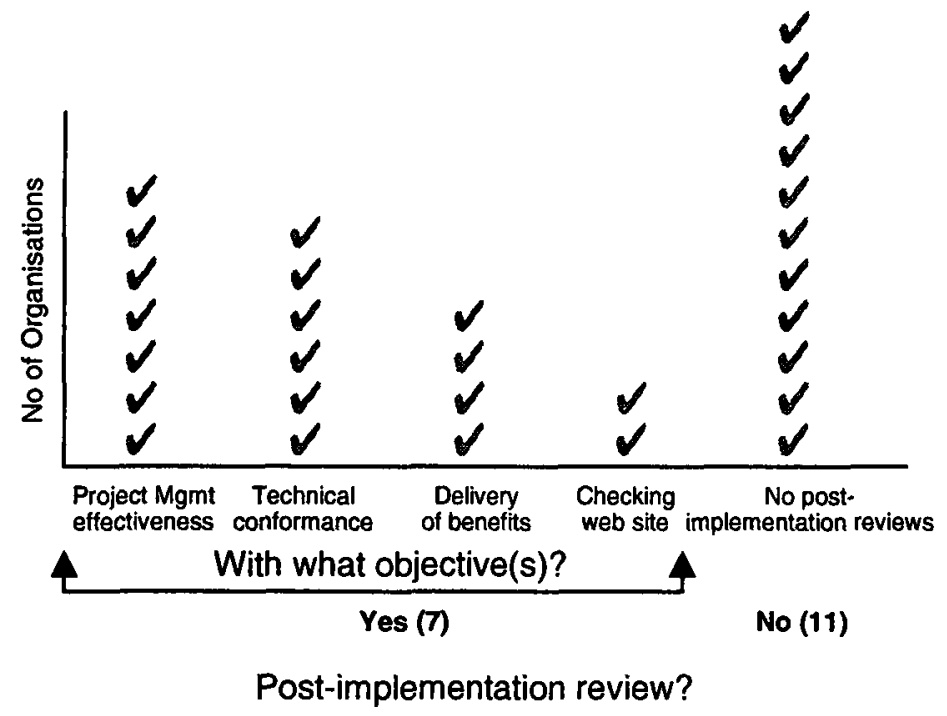

Figure 15: Post-Implementation Reviews of EC initiatives

To conclude the interviews, the executives were asked whether their organisation had derived "value for money" from their EC investment. No definition of this concept was offered, so hopefully, their overall "gut reaction" was being expressed. Figure 16 reveals the picture of responses. Those toward the "yes" end of the spectrum reported increases in efficiency, competitive positioning, and increased public awareness of their enterprise. 2 said "yes", but added that there had been no measurable benefits, 1 said "yes", only to quickly qualify the claim by adding that "it will in the future". Of interest to note however, were the 6 respondents $(31 \%)$ who were not persuaded that value for money had been derived.

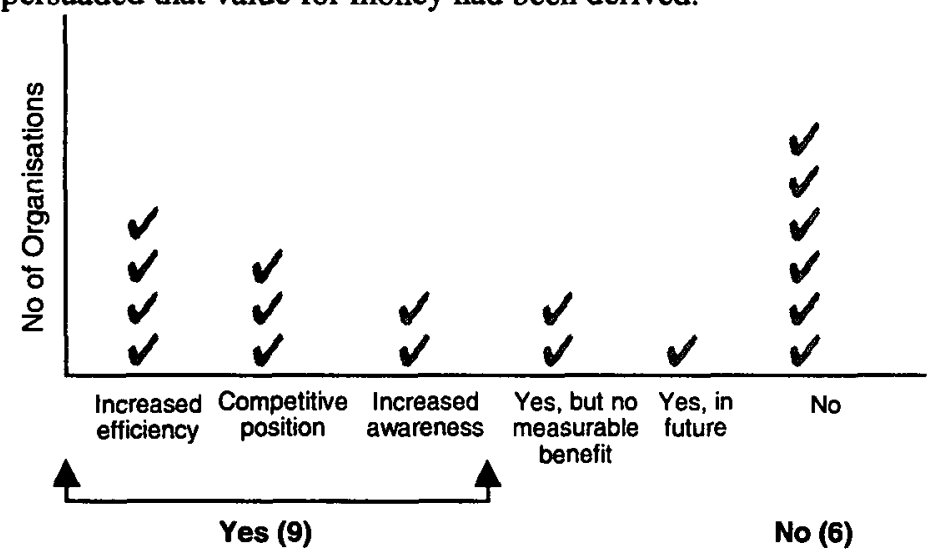

Figure 16: Have you derived "value for money" from EC investments?

Additional comments were proffered by some to support their feelings about getting value for money from EC. For a minority of the executives in this study, the venture into EC has been a positive and successful one, bringing lasting benefits and repositioning their organisations. More of those who chose to make a closing comment, however, seemed faintly to distinctly disappointed with their EC initiatives. One comment, in essence repeated by 3 or 4 of the participants, related to concerns that the initial costs for EC were perceived to be high, and once that hurdle was overcome, the expected benefits were not easy to achieve. Some talked about the difficulties they had experienced in firstly, anticipating all the costs they actually encountered, and secondly, in establishing appropriate measures for benefits. One executive described what he called an "expectation gap", the perception that what had been delivered to the organisation had been less than that anticipated. Echoing a similar sentiment, one executive commented that "I have been seduced by media hype!".

\section{DISCUSSION OF RESEARCH FINDINGS}

The study reveals an interesting picture amongst SMEs with respect to their EC initiatives, but does not inspire confidence in terms of their approach to evaluating their investments and managing the realisation of benefits from those investments. Although many participants expressed quite a degree of confidence that they would derive benefits from their EC investments (see Figure 7), other components of their responses did not really 
confirm this confidence, and indeed, their overall responses to the issue of deriving value for money did not present such assuredness (see Figure 16).

The organisations represented in this study in the main were at a relatively immature stage with respect to EC, had spent fairly substantial amounts in getting established (certainly enough to de-bunk the myth that EC is cheap!), and were anticipating fairly high on-going expenditure on EC. Despite this, they were generating little or no revenue from the EC initiative, and outlays did not appear to be matched by cost savings in most cases. Interestingly, and perhaps not surprisingly given these data, along with security, the most frequent concern about EC expressed by these executives had to do with whether there was any purpose in engaging in EC, whether it was "worthwhile". It also appeared that they felt somewhat "pushed" into EC, with external factors such as their competitiveness, market pressures and increased interest from trading partners and customers featuring highly in driving their EC investments. A picture emerges of organisations feeling impelled to become involved in EC at least in a minimal way, spending quite a lot of money in establishing and maintaining a presence, but deriving neither substantial revenues nor cost savings. Why might this be the case?

Previous argument suggests the need to consider the relationship between planning (establishing close links between IT investments and business objectives), an on-going life cycle approach to evaluation, and the proactive management of the realisation of business benefits from IT investments (McKay and Marshall 2001). If we consider the reported behaviours of respondents in this regard, an interesting picture emerges. Comparatively few claimed that planning for EC was integrated with their business planning, nor were there reported to be any mechanisms to link EC investments with business objectives. It is tempting to conclude therefore, that in many instances, planning for EC could best be described as an ad hoc activity, without there necessarily being a coherence between the overall business direction and objectives and the EC initiative.

Evaluation of the EC proposal also appeared somewhat haphazard: those that did rely on some recognised approach such as cost/benefit analysis (and they were in the minority), alighted upon a mechanism the efficacy of which has been questioned in the IS research literature (Willcocks and Lester 1997, Farbey et al. 1992). Many relied on intuition. If we consider the large proportion who subsequently felt that their evaluations had not proved satisfactory, it could be argued that neither approach (costbenefits or intuition) appears to have been particularly effective. Of particular concern was their failure during the evaluation activity to identify costs and potential benefits accurately, and to adequately quantify the "value" of those benefits.

When it came to the realisation of benefits, again a disturbing picture emerges of executives assuming that benefits will flow to their organisations just by making an investment: chance and personal belief that benefits would accrue were reasonably common. This is coupled with the fact that generally speaking, there were few measures of success in place, there were comparatively few post-implementation reviews, and when these were held, they generally focussed on checking technical specifications and project management performance. While the business world is far too complex to safely draw any definite causal relationships, could it be postulated that inadequate planning, evaluation and benefits management may have contributed to perceptions that organisations were not deriving value for money, and the view that they "had been seduced by media hype"?

The answer to that question lies outside the scope of this research, as we set out to explore and describe, not to explain. But the picture that emerged from this study does not suggest that SMEs are currently managing their EC initiatives in a particularly efficacious way, and thus, it is perhaps not completely surprising that they themselves echo some disappointment with the results they are achieving with respect to EC. Of interest was the fact that the results of our study mirror fairly closely the findings of Ward et al (1996), despite the different foci of the research (Ward et al. (1996) were considering IS/IT investments in large, private organisations).

\section{CONCLUSION}

While the study reported here has revealed some interesting and disturbing practices, it also seems to point to the need for further research. In the sample of organisations we looked at, there seemed a disturbing lack of planning, evaluation and proactive management of benefits with respect to their EC initiatives. Is this practice replicated across all their IS/IT investments? Can a stronger indication of causation be established between these behaviours and their disappointment with their EC initiatives? What sort of strategies and approaches could be adopted in order that better business outcomes for the organisation might be achieved? This study seems to pose more questions than it answers.

It was earlier argued in this paper that for countries in which a large proportion of their economic output is dependent on the activity of SMEs, participation in and deriving benefits from the new economy depends on individual SMEs successfully engaging in and managing a whole range of EC initiatives for positive business outcomes. Our study of the small sample of SMEs questions the extent to which this is being accomplished. Of vital importance, therefore, is to work towards helping SMEs achieve better outcomes with their EC endeavours. 


\section{REFERENCES}

Anderson Consulting (1998) e-Commerce: Our Future Today, http://www.ac.com

Australian Department of Communications, Information Technology and the Arts (DOCITA) (2000a)

Australia's E-commerce Report Card, http://www.noie.gov.au/ReportCard

Australian Department of Communications, Information Technology and the Arts (DOCITA) (2000b) E-

Commerce Beyond 2000. http://www.dcita.gov.au

Behrendorff, G., Fisher, J., Goldsworthy, M. A., Corbitt, B.and Perks, G. (1996) Advice on Electronic Commerce Programmes for Small to Medium-sized Enterprises (SMEs), http://www.cec.buseco.monash.edu.au/reports/dist/report.htm Canberra, Australia: Department of Industry Science and Tourism

Bryman, A. Research Methods and Organizational Studies. Routledge, London, 1989.

Crawford, J. (1998) NEWS: A Project to Get Smaller Enterprises On-line. Ultimo, NSW: Department of Industry, Science and Tourism (DIST), and Tradegate ECA.

Czerniawska, F. and Potter, G. (1998) Business in a Virtual World: Exploiting Information for Competitive Advantage, Macmillan Press, London.

Earl, M.J. (1994) Putting information technology in its place: a polemic for the nineties. In R.G. Galliers and B.S.H. Baker (eds.) Strategic Information Management: Challenges and Strategies in Managing Information Systems. Butterworth Heinemann, Oxford, pp76-90.

Ernst \& Young (2000a) Global On-line Retailing, http://www.ey.com.au

Ernst \& Young (2000b) Virtual Shopping in Australia, http://www.ey.com.au

Farbey, B., Land, F. and Targett, D. (1992) Evaluating investments in IT. Journal of Information Technology, $7(2): 100-112$.

Fowler, F.J. and Mangione, T.W. Standardized Survey Interviewing: Minimizing Interviewer-Related Error. Sage, Newbury Park, 1990.

Galliers, R.D. "Choosing appropriate information systems research approaches: a revised taxonomy." In Information Systems Research: Contemporary Approaches and Emergent Traditions. H.E. Nissen, H.K. Klein and R. Hirschheim (eds.) Elsevier Science Publishers, North Holland, 1991.

Kempis, R. and Ringbeck, J. (1999) Do IT Smart: Seven Rules for Superior Information technology Performance. Free Press, New York.

Laudon, K.C. and Laudon, J.P. (2000) Management Information Systems: Organization and Technology in the Networked Enterprise. $6^{\text {th }}$ ed. Prentice Hall, N.J.

Leedy, P.D. Practical research: Planning and Design $5^{\text {th }}$ ed. Macmillan, New York, 1993.

Marshall, P., Sor R. and McKay, J. (2000) Electronic Commerce and Car Retailing: An Industry Case Study. International Journal of Electronic Commerce Research. 1(1).

McKay, J and Marshall, P. (2001) The IT Evaluation and Benefits Management Life Cycle. In Van Grembergen, W. (Editor) IT Evaluation Methods and Management. Idea Publishing Group.

Neuman, W.L. Social research methods: qualitative and quantitative approaches. $3^{\text {rd }}$ ed. Allyn \& Bacon, Boston, 1997.

O'Connor, J. and Galvin, E. (1998) Creating value through eCommerce. Financial Times Management, London.

OECD (1998) SMEs and Electronic Commerce, Working Party on Small And Medium-sized Enterprises, Directorate for Science, Technology and Industry, Organization for Economic Co-operation and Development.

Small Business Index (1999) Survey of Computer Technology and E-commerce in Australian Small and Medium Business, http://www.pacificaccess.com .au

US Department of Commerce (1999) The Emerging Digital Economy II, http://www.ecommerce.gov/emerging.htm

Valli, C. and Marshall, P. "An initial study of Australian on-line bookstores." Paper accepted for presentation at $2^{\text {nd }}$ Annual Global Information Technology Management 2001 World Conference, Dallas, Texas, 10-12 June, 2001.

Ward, J., Taylor, P. and Bond, P. (1996) Evaluation and realisation of IS/IT benefits: an empirical study of current practice. European Journal of Information Systems, 4, 214-225.

Willcocks, L. and Lester, S. (1997) Assessing IT productivity: any way out of the labyrinth? In L. Willcocks, D. Feeny and G. Islei (eds.) Managing IT as a Strategic Resource. McGraw Hill, London.

Zwass, V. (2001) Structure and macro-level impacts of electronic commerce: from technological infrastructure to electronic marketplaces. http://mhhe.com/business/mis/zwass/ecpaper.html 